\title{
GENETIC ANALYSIS OF SOME AGRONOMIC AND FIBER TRAITS IN Gossypium hirsutum L. GROWN IN FIELD CONDITIONS
}

\author{
Muhammad Naeem KALEEM ${ }^{1}$, Iqrar Ahmad RANA ${ }^{2}$, Amir SHAKEEL ${ }^{1}$, Lori HINZE ${ }^{3}$, Rana Muhammad \\ ATIF ${ }^{4}$ and Muhammad Tehseen AZHAR ${ }^{* I}$ \\ ${ }^{1}$ University of Agriculture, Department of Plant Breeding and Genetics, Faisalabad, PAKISTAN, \\ ${ }^{2}$ University of Agriculture, Center of Agricultural Biochemistry and Biotechnology, Faisalabad, \\ PAKISTAN, \\ ${ }^{3}$ ARS-USDA,Crop Germplasm Research Unit, 2881 F\&B Road, College Station, TX 77845, \\ ${ }^{4}$ University of Agriculture, Centre for Advanced Studies in Agriculture and Food Security, Faisalabad, \\ PAKISTAN \\ *Corresponding author: tehseenpbg@uaf.edu.pk
}

Received: 21.03 .2016

\begin{abstract}
Cotton plant faces several stresses during its life cycle that limit seed cotton yield and fiber production. Lack of availability of potential genotypes is one of the stress main factors that the farmer community faces. A complete diallel mating design was used to study combining ability of a set of upland cotton genotypes developed in Pakistan. Five parents namely, IR-NIBGE-3, FH-166, KZ-189, MS-40 and B-557 were hybridized in a glasshouse and $F_{1}$ seeds with five parents were planted in field conditions. The combining ability analysis revealed that IR-NIBGE-3 is a good general combiner for gin turnout and fiber strength, while KZ-189 and FH-166 are good general combiners for number of bolls per plant, yield of seed cotton and fiber length. The combination of FH-166 $\times$ B-557 and MS-40 $\times$ B- 557 exhibited the best specific combining ability for number of bolls per plant, yield of seed cotton and gin turnout; whereas combination of KZ-189 × B-557 and MS-40 $\times$ KZ-189 were the best for fiber length and fiber strength, respectively. Positive and significant reciprocal effects signify the role of female parents for their use in hybridization. SCA variance was greater than GCA variance for all traits indicating the importance of non-additive effects in genetic control of these traits. This study indicates that this population can be used for selection of transgressive segregants for fiber and yield related traits and superior parents can be used in hybridization programs.
\end{abstract}

Keywords: Additive and non-additive effects, combining ability, gene action, quantitative traits, Upland cotton

\section{INTRODUCTION}

Pakistan is an agricultural country and the income of Pakistani farmers depends upon the successful cultivation of field crops including cotton, wheat, rice, maize and sugarcane. Of all these crops, cotton fulfills fiber needs for textile industry; its seed is source of edible oil, and seed cake for livestock. Agriculture contributes $21 \%$ to gross domestic product (GDP) of Pakistan while cotton contributes $1.6 \%$ to the total GDP (Anonymous 2013-14). Therefore, this cash crop is of vital importance to national economy and continuous improvement is required.

Before starting any breeding program, the information about parents for certain traits is very important so that they can produce efficient and potential progenies. This can be done with the use of biometrical approaches available to plant breeders. One can assess and interpret the population for various agronomic and non-agronomic traits of crop plant. Griffing's approach is widely used in crop plants because term combining ability (general and specific) deals with calculating breeding value, assessing potential of parental lines and development hybrids (Griffing, 1956). Parents with highest GCA effects indicate the role of additive type of gene action involved in the expression of particular trait. Specific combining ability effects identify the best combinations from the population for hybrid development, they also identify complementary alleles for trait performance (Kearsey and Pooni, 1996). Studies of Shakeel et al. (2001), Ahuja and Dhayal (2007) indicated that seed cotton yield, number of bolls per plant and boll weight were influenced by nonadditive gene effects, in contrast studies of Khan and Idris (1995) and Kumaresan et al. (1999) which revealed that both additive and non-additive gene effects are important for controlling number of bolls and seed cotton yield. Lukange et al. (2007) reported the presence of additive gene effects for fiber fineness and fiber strength with nonadditive gene action for fiber length. Combining ability analysis has been used efficiently for making improvements in cotton (Azhar and Naeem, 2008), wheat 
(Gowda et al., 2012) and rice (Saidaiah et al., 2010) and other field crops. The combining ability gives information about additive and non-additive gene effects involve in controlling various yield and fiber traits in cotton, as Baloch et al. (1997), Hassan et al, 1999 and 2000, Ahuja and Dhayal (2007), Preetha and Raveendran (2008) reported Non-additive gene action for fiber length and fiber strength. With the passage of time information on contribution of various parameters to yield is reported for instance by Zeng et al. (2014) who mentioned the contribution of six yield components to seed cotton yield ranging from 1.6 to $21 \%$ of total variation for lint yield. The greatest contributions to lint yield come from four components i.e. lint percentage, lint weight per seed, lint weight per unit seed surface area and lint number per unit seed surface area. This information guides the cotton breeders that these four parameters should be considered important while making selection for genetic improvement in seed cotton.

Ragsdale (2003) performed diallel analysis of crosses between 8 cotton genotypes over two years, calculated GCA and SCA for various traits and cross combinations respectively. They found significant variation among traits from within boll yield. They also found variation between years and suggested that selection should be done over the years, but they did not find significant effects of temperature on yield. Zeng (2014) reviewed gene action and combining ability for lint yield and fiber quality parameters and reported that over the years even one line has not been identified in the US which has better GCA for fiber quality parameters and simultaneously for lint yield. The lines which have good GCA for fiber quality parameters and usually poor yielders Keeping in view the importance of combining ability analysis, efforts have been made in present study to identify superior combinations from 25 families including five parents of upland cotton. The information will be helpful for the selection of superior parental genotypes and specific combinations for the development of cotton cultivars with improved yield and fiber characteristics.

\section{MATERIALS AND METHODS}

Five contrasting genotypes of Gossypium hirsutum L. namely IR-NIBGE-3 (plant height of 90-100 cm, medium bolls with oval shape, good opening and medium leaf size) FH-166 (plant height of $100 \mathrm{~cm}$, medium size of bolls, dense foliage with broad leaf), KZ-189 (plant height of $100-130 \mathrm{~cm}$, big boll size, good opening, medium leaf size and erect plant type), MS-40 (big boll size, high GOT\%, broad leaves with open type plant) and B-557 (medium size of leaves with medium boll size, bushy plant with plant height of $90-130 \mathrm{~cm}$ ) were selected from germplasm available with Cotton Research Group at Department of Plant Breeding and Genetics, University of Agriculture, Faisalabad (Pakistan). The pots were filled with $9 \mathrm{~kg}$ of soil having $\mathrm{pH} 8.4$, organic matter $0.98 \%$, saturation percentage $28 \%$, available phosphorus 29.3 ppm, and potassium $138 \mathrm{ppm}$. The pots were placed in glass house during November, 2014. Seeds of each entry were soaked in tap water for 10 hours, and five seeds of each parental line were sown $2 \mathrm{~cm}$ deep in each pot. Each parent was grown in 10 pots resulting in 50 pots in total. Later on young seedlings were thinned to two plants per pot at $15 \mathrm{~cm}$ distance from each other. The temperature of the glass house was maintained at (day/night) $30 / 21^{\circ} \mathrm{C} \pm$ $3^{\circ} \mathrm{C}$ using steam and gas heaters. The most appropriate temperature for seed germination and plant growth is 20$30{ }^{\circ} \mathrm{C}$ (Reddy et al., 1998; Ali et al., 2008). In addition to sunlight, artificial light was used after sunset to provide a photoperiod of 12-14 hours. The parents started to flower during February, 2015 and were crossed in all possible combinations. During bud formation stage, about thirty buds were emasculated in evening time and pollinated on next day in morning hours to produce sufficient quantity of $\mathrm{F}_{0}$ seeds. Some of the buds were also covered with glassine bags to produce selfed seed. At maturity, seed cotton from the crossed and selfed bolls were picked, and ginned with a single roller electric gin in the laboratory to obtain $\mathrm{F}_{0}$ seed.

During April 2015, the seed of these five parents along with 20 crosses (10 direct and 10 indirect) was planted in three replication following randomized complete block design (RCBD) at cotton farm of the Department. Plants and rows were spaced 30 and $75 \mathrm{~cm}$ apart, respectively. All agronomic practices were conducted uniformly throughout the growing season to minimize environmental variability in the plant population. When plants started to flower, some of the unopened flowers were covered with glassine bags to avoid any chance of cross pollination through insects to obtain $F_{1}$ seed. At maturity, seed cotton from all selfed plants in each family was picked separately, and ginned to obtain seeds for $F_{2}$ generation. At maturity, data was collected on various traits contributing to yield, namely, plant height, number of bolls per plant, and gin turnout (weight of lint/weight of seed cotton $\times 100)$. The fiber traits like staple strength (g/tex) and staple length $(\mathrm{mm})$ were determined from lint by using High Volume Instrument 900 (HVI-900, Uster Technologies Ltd, Switzerland). Means of the data were biometrically analyzed with software of Statistical Analysis System (SAS Version 9.2) to assess the significant and non-significant differences among the $F_{1}$ hybrids for certain traits following the method of Steel et al. (1997). The effects of additive and non-additive genes were determined through combining ability analysis as suggested by Griffing's Method 1. (1956).

\section{RESULTS}

Highly significant differences $(\mathrm{P} \leq 0.01)$ were observed in the five parental genotypes and crosses of G. hirsutum L. for selected traits of yield and fiber except only significant difference $(\mathrm{P} \geq 0.05)$ for plant height (Table 1). Mean squares of combining ability analysis are also presented in Table 1. The analysis of the data following Griffing approach showed the presence of highly significant $(\mathrm{P} \leq 0.01)$ mean squared due to SCA effects for number of bolls per plant and seed cotton yield, except fiber strength where GCA effects are significant $(\mathrm{P} \leq 0.05)$ effects for fiber strength while effects of GCA were nonsignificant $(\mathrm{P} \geq 0.05)$ for plant height, gin turnout and fiber 
length. Highly significant $(\mathrm{P} \leq 0.01)$ mean squares were observed due to SCA and reciprocal effects for yield and fiber related traits included in this study. Mean values and variances of five parents as well as direct and indirect crosses showed the presence of variation for selected yield and fiber traits (Table 2). The high values of GCA were found for B-557 (2.153) and MS- 40 (1.889) for plant height while the lowest values for IR-NIBGE-3 (-2.076) and FH-166 (-1.330) were observed (Table 3). Since our breeding objective was to decrease plant height, the parents with the lowest GCA, IR-NIBGE-3 and FH-116, were the best general combiners for this trait. The highest negative values of SCA for plant height were observed for KZ-189 × FH-166 (-14.672) followed by MS-40 ×IRNIBGE-3 (-9.967) and IR-NIBGE $\times$ B-557 (-9.211), which indicated that these three crosses are the best specific combinations for plant height.

Table 1. Mean squares from analysis of variance and combining ability analysis of yield and fiber traits of Gossypium hirsutum L.

\begin{tabular}{llllllll}
\hline $\begin{array}{l}\text { Source of } \\
\text { variation }\end{array}$ & D.F. & Plant height & $\begin{array}{l}\text { No. of bolls } \\
\text { per plant }\end{array}$ & $\begin{array}{l}\text { Seed cotton } \\
\text { yield }\end{array}$ & Gin turnout & $\begin{array}{l}\text { Fiber } \\
\text { length }\end{array}$ & $\begin{array}{l}\text { Fiber } \\
\text { strength }\end{array}$ \\
\hline Replication & 2 & $1.398^{\text {N.S. }}$ & $51.24^{\text {N.S. }}$ & $83.864^{\text {N.S. }}$ & $1.849^{\text {N.S. }}$ & $0.572^{\text {N.S. }}$ & $0.698^{\text {N.S. }}$ \\
Genotype & 24 & $219.499^{*}$ & $782.214^{* *}$ & $2545.109^{* *}$ & $25.581^{* *}$ & $12.235^{* *}$ & $5.366^{* *}$ \\
GCA & 4 & $36.695^{\text {N.S. }}$ & $247.052^{* *}$ & $1748.201^{* *}$ & $4.975^{\text {N.S. }}$ & $0.418^{\text {N.S. }}$ & $0.562^{*}$ \\
SCA & 10 & $54.837^{* *}$ & $392.141^{* *}$ & $712.917^{* *}$ & $10.656^{* *}$ & $3.556^{* *}$ & $1.526^{* *}$ \\
Reciprocal & 10 & $106.086^{* *}$ & $138.811^{* *}$ & $623.883^{* *}$ & $7.820^{* *}$ & $6.064^{* *}$ & $2.542^{* *}$ \\
$\sigma^{2}$ (GCA) & & 3.476 & -25.468 & 213.683 & 1.067 & -0.596 & -0.180 \\
$\sigma^{2}$ (SCA) & & 9.523 & 221.822 & 414.135 & 4.341 & 1.954 & 0.781 \\
\hline
\end{tabular}

N.S. - non significant; * - significant at the 0.05 probability level; ** - significant at the 0.01 probability level

Table 2. Mean performance and variance of parents along with crosses (direct and indirect) of Gossypium hirsutum L.

\begin{tabular}{|c|c|c|c|c|c|c|}
\hline Parents & Plant height (mm) & No. of bolls per plant & $\begin{array}{l}\text { Seed cotton yield } \\
(\mathrm{g})\end{array}$ & $\begin{array}{c}\text { Gin turnout } \\
(\%)\end{array}$ & $\begin{array}{c}\text { Fiber length } \\
(\mathrm{mm})\end{array}$ & $\begin{array}{c}\begin{array}{c}\text { Fiber strength } \\
(\mathrm{g} / \mathrm{tex})\end{array} \\
\end{array}$ \\
\hline IR-NIBGE-3 & 108.5 & 25.7 & 56.3 & 39.3 & 27.6 & 26.2 \\
\hline FH-166 & 113.5 & 49.7 & 101.7 & 33.2 & 28.9 & 27.3 \\
\hline KZ-189 & 101.2 & 45.3 & 90.6 & 37.3 & 27.7 & 24.9 \\
\hline MS-40 & 108.1 & 46.4 & 91.7 & 41.3 & 25 & 26.1 \\
\hline B-557 & 112.8 & 34.7 & 77.7 & 37.1 & 25.5 & 25.7 \\
\hline Variance of parents & 24.107 & 98.768 & 305.58 & 9.068 & 2.673 & 0.758 \\
\hline \multicolumn{7}{|l|}{ Cross combinations } \\
\hline \multirow[t]{2}{*}{ IR-NIBGE-3 × FH-166 } & 102.4 & 30.3 & 82 & 37.4 & 23.7 & 27 \\
\hline & 94.6 & 38.3 & 67.4 & 37.6 & 29.4 & 25.7 \\
\hline \multirow{2}{*}{ IR-NIBGE-3 × MS-40 } & 99.4 & 51.3 & 95.4 & 37.4 & 28.2 & 24.6 \\
\hline & 119.3 & 51.7 & 98.2 & 35.7 & 29.3 & 27.9 \\
\hline \multirow[t]{2}{*}{ IR-NIBGE-3 × KZ-189 } & 107.3 & 56.7 & 59.1 & 38.9 & 27.6 & 23.9 \\
\hline & 117.2 & 51.7 & 84 & 36.4 & 25 & 25.5 \\
\hline \multirow[t]{2}{*}{ IR-NIBGE-3 × B-557 } & 93.5 & 36.7 & 89.5 & 42.9 & 27.4 & 25.8 \\
\hline & 103.1 & 45.7 & 65.5 & 42 & 24.7 & 25.1 \\
\hline \multirow[t]{2}{*}{ FH-166 × MS-40 } & 101 & 48.3 & 90.3 & 36.6 & 25.4 & 24.5 \\
\hline & 108.3 & 52.3 & 82.7 & 39.6 & 28.6 & 24.6 \\
\hline \multirow[t]{2}{*}{ FH-166 × KZ-189 } & 89.7 & 45.7 & 85.5 & 39.1 & 27.7 & 22.9 \\
\hline & 119 & 45.3 & 69 & 39.8 & 25.3 & 26.3 \\
\hline \multirow[t]{2}{*}{ FH-166 × B-557 } & 103 & 50.3 & 86.8 & 41.6 & 26.3 & 26.3 \\
\hline & 116 & 55.3 & 1.5 .1 & 41 & 27.9 & 24.4 \\
\hline \multirow[t]{2}{*}{ MS-40 $\times$ KZ-189 } & 111.3 & 46 & 88.7 & 41.2 & 27.9 & 27.9 \\
\hline & 102.1 & 53.3 & 82.1 & 38.6 & 24.6 & 25.1 \\
\hline \multirow[t]{2}{*}{ MS-40 × B-557 } & 104.2 & 50.7 & 77.7 & 36.4 & 24.2 & 25.5 \\
\hline & 120 & 52.3 & 93.9 & 37.1 & 29.5 & 26.3 \\
\hline \multirow[t]{2}{*}{ KZ-189 × B-557 } & 104.2 & 50.3 & 79.7 & 39.2 & 31.8 & 22.5 \\
\hline & 119 & 27 & 65.4 & 36.2 & 27.8 & 25.9 \\
\hline Variances (Direct crosses) & 39.458 & 59.560 & 101.273 & 15.296 & 5.342 & 3.021 \\
\hline Variances (Indirect crosses) & 83.534 & 76.485 & 154.981 & 4.624 & 4.312 & 1.028 \\
\hline
\end{tabular}

The values in non-italic are the means of direct combinations while italic values are means of reciprocal combinations. 
Table 3. Estimates of general and specific combining abilities for yield and fiber traits of Gossypium hirsutum L.

\begin{tabular}{|c|c|c|c|c|c|c|}
\hline Parents & Plant height (mm) & No. of bolls per plant & $\begin{array}{c}\text { Seed cotton yield } \\
(\mathrm{g})\end{array}$ & $\begin{array}{c}\text { Gin turnout } \\
(\%)\end{array}$ & $\begin{array}{c}\text { Fiber length } \\
(\mathrm{mm})\end{array}$ & $\begin{array}{c}\begin{array}{c}\text { Fiber strength } \\
(\mathrm{g} / \mathrm{tex})\end{array} \\
\end{array}$ \\
\hline IR-NIBGE-3 & -2.076 & -6.393 & -16.657 & 0.990 & -0.030 & 0.274 \\
\hline FH-166 & -1.330 & 2.673 & 13.120 & -0.168 & 0.130 & 0.114 \\
\hline KZ-189 & -0.637 & 5.907 & 13.818 & -0.981 & 0.230 & 0.104 \\
\hline MS-40 & 1.889 & 1.507 & -6.885 & 0.149 & -0.310 & -0.296 \\
\hline B-557 & 2.153 & -3.693 & -3.428 & 0.010 & -0.020 & -0.196 \\
\hline $\mathrm{Cd} 1(\mathrm{gi}-\mathrm{gl})$ & 1.63 & 3.86 & 3.63 & 1.60 & 0.46 & 0.40 \\
\hline \multicolumn{7}{|l|}{ Cross Combinations } \\
\hline \multirow[t]{2}{*}{ IR-NIBGE-3 × FH-166 } & -5.557 & -16.507 & -10.388 & 2.630 & -0.630 & 0.446 \\
\hline & 3.887 & -4.000 & -16.260 & 4.922 & -2.850 & 0.650 \\
\hline \multirow[t]{2}{*}{ IR-NIBGE-3 × MS-40 } & 4.607 & 10.427 & 27.994 & -0.787 & 1.470 & 0.356 \\
\hline & -9.967 & 0.833 & -3.883 & 2.548 & -0.550 & -1.650 \\
\hline \multirow{2}{*}{ IR-NIBGE-3 × KZ-189 } & 4.985 & -3.254 & 7.435 & -2.537 & -0.440 & -0.794 \\
\hline & -4.946 & 7.500 & -36.968 & 1.252 & 1.300 & -0.800 \\
\hline \multirow[t]{2}{*}{ IR-NIBGE-3 × B-557 } & -9.211 & 0.307 & -2.543 & 2.397 & -0.980 & -0.144 \\
\hline & -4.772 & -4.500 & -0.037 & 0.413 & 1.350 & 0.350 \\
\hline \multirow[t]{2}{*}{ FH-166 × MS-40 } & -0.799 & -1.807 & -12.360 & 0.149 & -0.440 & -1.184 \\
\hline & -3.617 & -8.000 & -1.350 & -1.500 & -1.600 & -0.050 \\
\hline \multirow[t]{2}{*}{ FH-166 × KZ-189 } & -3.617 & -11.240 & -16.667 & 0.409 & -0.400 & -0.734 \\
\hline & -14.672 & 2.167 & 6.783 & -0.323 & 1.200 & -1.700 \\
\hline \multirow[t]{2}{*}{ FH-166 × B-557 } & 1.259 & 15.793 & 28.144 & 2.384 & -0.090 & -0.084 \\
\hline & -6.502 & -8.000 & -22.128 & 0.363 & -0.800 & 0.950 \\
\hline \multirow[t]{2}{*}{ MS-40 × KZ-189 } & -1.965 & -3.807 & -9.702 & 1.709 & -0.750 & 1.176 \\
\hline & 4.597 & -12.167 & -8.727 & 1.303 & 1.650 & 1.400 \\
\hline \multirow[t]{2}{*}{ MS-40 × B-557 } & 3.156 & 8.227 & 9.253 & -1.309 & -0.440 & 0.476 \\
\hline & -7.938 & -2.333 & -3.102 & -0.334 & -2.650 & -0.400 \\
\hline \multirow[t]{2}{*}{$\mathrm{KZ}-189 \times \mathrm{B}-557$} & 3.727 & -8.207 & -7.297 & -1.506 & 3.050 & -0.824 \\
\hline & -3.742 & 17.167 & 29.155 & 1.533 & 2.000 & -1.700 \\
\hline cd1 (sij - sik) & 10.925 & 7.737 & 7.264 & 3.214 & 0.917 & 0.811 \\
\hline cd1 (rij - rkl) & 12.215 & 8.650 & 8.122 & 3.593 & 1.025 & 0.906 \\
\hline
\end{tabular}

The values in italic are the specific combining ability effects of reciprocal combinations. Cd is critical differences for GCA, SCA and reciprocal combinations.

The relative magnitude of the estimates of general combining ability for number of bolls per plant ranged from a high of 5.907 (KZ-189) to a low of -6.393 (IRNIBGE-3) (Table 3). The parents, KZ-189 (5.907), FH166 (2.673) and MS-40 (1.507) attained positive values, which indicated that these genotypes were good general combiners to increase the number of bolls per plant. The potential of the parents to nick with each other was compared in their combinations. Although IR- NIBGE-3 $\times$ MS-40, IR-NIBGE-3 × B-557, FH-166 × B-557 and MS$40 \times$ B-557 attained positive values of 10.427, 0.307, 15.793 and 8.227 respectively while the combination of IR-NIBGE-3 × B-557 was significantly different and had lower value than the other three combinations when estimating SCA effects for number of bolls per plant. Among the reciprocal crosses with positive effects, the combinations of - MS-40 $\times$ IRNIBGE-3 (0.833), KZ-189 $\times$ IR-NIBGE-3 (7.500), and KZ-189 × FH-166 (2.167) were significantly different from B-557 $\times$ KZ189(17.167). GCA effects of the five parents for seed cotton yield were also estimated, and two parents, KZ-189 (13.818) and FH-166 (13.12), attained positive values to indicate they were the best general combiners to increase yield of seed cotton (Table 3 ). There were no significant differences between the GCA effects for these two parents. Both additive and non-additive gene effects were involved in the inheritance of this trait (Table 1). The performance of the parents in various combinations showed that six combinations (KZ-189 x B-557, FH-166 $\times$ B-557, IR- NIBGE-3 $\times$ MS-40, MS-40 × B-557, IRNIBGE-3 $\times$ KZ-189 and KZ-189 $\times$ FH-166 with 29.155,
28.144, 27.994, 9.253, 7.435 and 6.783, respectively) attained positive values for seed cotton yield. The combinations of IR-NIBGE-3 $\times$ MS-40 (27.994) and FH$166 \times$ B-557 (28.144) were not significantly different from each other but significant differences were observed with IR-NIBGE-3 $\times$ KZ-189 (7.435) and MS-40 × B-557 (9.253) (Table 3). There were no significant differences among GCA effects for gin turnout although the genotypes IR-NIBGE-3 (0.99) and MS-40 (0.149) tended to increase gin turnout. In contrast, there were significant differences among specific combinations for gin turnout. Most notably, FH-166 $\times$ IR-NIBGE-3 increase gin turnout approximately $5 \%$. Similar to gin turnout, there were no significant differences among GCA effects for fiber length. BothKZ-189 (0.230) and FH-166 (0.130) had an increasing effect on fiber length, but they were not statistically different. When comparing specific crosses, KZ- $189 \times$ B-557 (3.05) and its reciprocal, B-557 $\times$ KZ189 (2.00), showed the best specific combining abilities for fiber length. The biometrical analysis for fiber strength revealed that parents, IR- NIBGE-3 (0.274), FH-166 $(0.114)$ and KZ-189 (0.104) possessed positive values and were the best general combiners for fiber strength. Although IR-NIBGE-3 had the highest value, statistically, it was not different from KZ-189 and FH-166, suggesting similar potential for fiber strength amongst the three parents.

The comparison of varietal combinations showed that eight combinations attained positive values that tended to increase fiber strength. The presence of high reciprocal 
effects of various combinations in the presented data set is interesting and helpful for selection of superior combination. Like KZ-189 $\times$ MS-40 showed the highest and positive reciprocal effects for plant height. More number of bolls is due to high reciprocal effects contributed by B-557 $\times$ KZ-189 and KZ-189 $\times$ IRNIBGE-3. B-557 $\times$ KZ-189 also showed highest positive and reciprocal effects for yield of seed cotton. The combination of FH-166 $\times$ IR-NIBGE-3 showed high reciprocal effects for ginning out turn as well as fiber strength whereas highest effects for staple strength were observed from B-557 $\times$ FH-166. Fiber length is also one of the important traits, high reciprocal effects were also positive from some of the crosses of KZ-189 $\times$ MS-40, KZ-189 × IR-NIBGE-3 and KZ-189 × FH-166.

\section{DISCUSSION}

Yield and fiber quality improvement is an important objective in any cotton breeding programs around the globe, but the genetic constitution of these traits is not completely understood. The biometrical analyze the data revealed that plant height, number of bolls per plant, seed cotton yield, gin turnout, fiber length and fiber strength were genetically controlled and inherited as other traits in the plants. The existed genetic variability in each character in these populations was further partitioned into various components i.e. general and specific combining ability. The comparison of five parents for GCA revealed that KZ-189 was found to be the best general combiner for number of bolls, seed cotton yield and fiber length whereas FH-166 was observed to be a good general combiner for fiber strength, number of bolls per plant and seed cotton yield. The outstanding parents with good general combining ability are recommended for the production of potential hybrids (Irfanullah et al., 1994; Azhar and Naeem, 2008). This type of information is also reported in present findings such as FH-166 $\times$ B-557 for number of bolls and yield of seed cotton whereas KZ-189 $\times$ B-557 is identified good combination for fiber length and strength.

Most of the time good combinations come from the hybridization of good parent but some time parents with poor GCA can give rise potential hybrids. As IR-NIBGE3 was not appear as a good general combiner for most of the traits, when it was crossed with other parents like combination of IR-NIBGE-3 $\times$ MS-40 (Table 3) showed good specific combining ability for number of bolls per plant, plant height, yield of seed cotton and fiber length and this information can be supported by the findings of Azhar and Rana (1993), Azhar and Khan (2005) and Shakeel et al. (2012). Non-additive genetic effects were found to be important for number of bolls per plant and this is supported by the findings of Neelima et al. (2004), Rauf et al. (2006) and Kiani et al. (2007), while additive effects were observed in the inheritance of number of bolls per plant by Shakooret al, (2010), and Ashokkumar and Ravikesavan (2010). The SCA variance was greater than the GCA variance for all six traits, thus indicating the presence of non-additive gene action (Shanthi and Selvaraj, 1995; Punitha and Raveendran, 1999; Punithaet al., 1999; Saravanan et al., 2010). It is observed from the positive and high values of reciprocal effects that combination of B-557 $\times$ KZ-189 could be used for the number of bolls per plant, yield of seed cotton and ginning out turn. The single crosses which showed positive and non-significant reciprocal effects could be used for the exploitation of yield contributing traits (Khan and Khan, 1985 and Rauf et al., 2005; Imran et al., 2012). Interesting all these yield related traits of upland cotton are positively correlated (Ahmad et al, 2008;Salahuddin et al., 2010). Traits under this type of genetic control can be improved by using heterosis breeding programs.

It is concluded that genetic variation is present in this population and parents with best general combining ability can be utilized efficiently but in present scenario the combining ability should be assessed with Bt-cotton varieties. Although it was not a big experiment but the presence of potential combinations with good specific combining ability for yield and fiber related are encouraging for cotton breeders. It is suggested the parents and specific combinations identified here could be utilized for breeding of potential genotypes of cotton for making improvement in agronomic and fiber traits.

\section{ACKNOWLEDGEMENT}

The authors of manuscript highly appreciate the efforts of supporting staff in greenhouse and cotton research farm of the Department of Plant Breeding and Genetics, University of Agriculture, Faisalabad-Pakistan.

\section{LITERATURE CITED}

Ahmad, W., N.U. Khan, M.R.Khalil, A. Parveen, U. Aimen,M. Saeed, Samiullah, S.A. Shah. 2008. Genetic variability and correlation analysis in upland cotton. Sarhad J. Agric.24: 573-580.

Ahuja, S. L., L. S. Dhayal. 2007. Combining ability estimates for yield and fibre quality traits in $4 \times 13$ line $\times$ tester crosses of Gossypium hirsutum. Euphytical153:87-98.

Ali, M.A., I.A. Khan, S.I. Awan, S. Ali,S. Niaz. 2008. Genetics of fibre quality traits in cotton (Gossypium hirsutum L.). Aust. J. Crop Sci. 2: 10-17.

Anonymous, 2013-14 Economic survey of Pakistan.Ministry of Food, Agriculture and Livestock, Economic Advisor Wing, Islamabad, Pakistan.

Ashokkumar, K., R. Ravikesavan. 2010. Combining ability estimates for yield and fibre quality traits in line $x$ tester crosses of Upland cotton (Gossypium hirsutum). International Journal of Biology 2: 179-189.

Azhar, F.M., M. Naeem. 2008. Assessment of cotton (Gossypium hirsutum) germplasm for combining abilities in fiber traits. Journal of Agriculture and Social Sciences4: 129-131.

Azhar, M.T.,A.A. Khan. 2005. Combining ability analysis of seed cotton yield and its components in Gossypium hirsutum L. Pakistan J. Sci. Ind. R. 48: 385-361.

Azhar. F.M., A.H. Rana. 1993. Genetic analysis of three development plant characteristics in upland cotton. Pak. J. Agr. Sci. 30: 439-42.

Baloch, M.J., H.U. Butto, A.R. Lakho. 1997. Combining ability estimates in $5 \times 5$ highly adapted tester lines crosses with pollinator inbreds of cotton (Gossypium hirsutum L). Pakistan J. Sci. Ind. R.40: 95-98. 
Gowda, M., C.F.H.Longin, V. Lein, J.C. Reif. 2012. Relevance of specific versus general combining ability in winter wheat. Crop Science 52: 2494-2500.

Griffing, B. 1956.Concepts of general and specific combining ability in relation to diallel system of crossing. Aust. J. Biol. Sci.9: 463-493.

Hassan, G., G. Mahood, A. Razzaq, Hayatullah. 2000 Combining ability in inter-varietal crosses of Upland cotton (Gossypium hirsutum L.). Sarhad J. Agric.16: 407-410.

Hassan, G., G. Mahood, N. U. Khan, A. Razzaq. 1999. Combining ability and estimates in a diallel cross of cotton. Sarhad J. Agric.15: 563-568.

Irfanullah, M., A. Khan, H.A. Sadaqat, A.A. Khan. 1994. Potentials of combining ability for yield and lint quality traits in G. hirsutum L. J. Agric. Res. 32: 363-7.

Kearsey, M.J., H.S. Pooni. 1996. The genetical analysis of quantitative traits. 1. ed. Chapman and Hall London, United Kingdom

Khan, M.A., A.A. Khan.1985. Estimation of combining ability effects in G. hirsutum crosses. The Pakistan Cottons 29: 3342.

Khan, T.M., M.A. Idris. 1995. Inheritance of boll weight, boll number and yield of seed cotton in upland cotton (Gossypium hirsutum L.). Sarhad J. Agri.11: 599-605.

Kiani, G., G.A. Nematzadeh, S.K. Kazemitabar, O. Alishah. 2007. Combining ability in

cotton cultivars for agronomic traits. Int. J. Agr. Biol.9: 521-522.

Kumaresan, D., P. Senthilkumar, J. Ganesan. 1999. Combining ability studies for quantitative traits in cotton (Gossypium hirsutum L.). Madras Agric. J. 18: 430-432.

Lukange, E.P., M.T. Labuschagne, L. Herselman. 2007. Combining ability for yield and fiber characteristics in Tanzanian cotton germplasm. Euphytica161: 383-389.

Neelima, S., V.C. Reddy, A.N. Reddy. 2004. Combining ability studies for yield and yield components in American cotton (Gossypium hirsutum L.). Annals Agric. Biol. Res. 9: 1-6.

Preetha, S., T.S. Raveendran. 2008. Combining ability and heterosis for yield and fiber quality traits in line $\times$ tester crosses of Upland cotton (G. hirsutum. L). Int. J. Plant Breed. Genet.2: 64-74.

Punitha, D., T.S. Raveendran. 1999. Heterosis and combining ability studies for quantitative characters in coloured linted cotton genotypes (Gossypium hirsutum $\times$ Gossypium barbadense). Crop Research 18: 423-429.

Punitha, D., T.S. Raveendran, D.M. Kavitha. 1999. Combining ability studies for yield and quality traits in interspecific coloured linted cotton (Gossypium hirsutum $\times$ Gossypium barbadense). PKV Research J.23: 17-20.

Ragsdale, I.P. 2003.Diallel analysis of within boll seed yield components and fiber properties in upland cotton (Gossypium hirsutum L) and breeding potential for heat tolerance. PhD Thesis Texas A \& M University, USA.

Rauf, S., Khan, T.M., Nazir S, 2005.Combining ability and heterosis in Gossypium hirsutum L. Int. J. Agri. Biol. 7: 109113.

Rauf, S., H. Munir, S. M. A. Basra, E. Abdullojon. 2006. Combining Ability Analysisin Upland Cotton (Gossypium hirsutum L.).Int. J. Agr. Biol.08: 341-343.

Reddy, K., Robana, R.R.R., Hodges, H.F., Liu, X.J., Mackinion, J.M.1998.Interaction of CO2 enrichment and temperature on cotton growth and leaf characteristics.Environ Exp. Bot.39:117-129.

Saidaiah, P., S.S. kumar and M.S. Ramesha. 2010. Combining ability studies for development of new hybrids in rice over environments. Agricultural Science 2: 225-233.

Saravanan, N.A., R. Ravikesavan, T.S. Raveendran. 2010. Combining ability analysis for yield and fiber quality parameters in intraspecific hybrids of $G$. hirsutum L. Electronic Journal of Plant Breeding 1: 856-863.

Shakeel, A., I.A. Khan, F.M. Azhar. 2001. Study pertaining to the estimation of gene action controlling yield and related traits in upland cotton. J. Bio. Sci.1: 67-70.

Shakeel, A., S. Ahmad, M. Naeem, M.H.N. Tahir, M.F. Saleem, S. Fareed, W. Nazeer. 2012. Evaluation of Gossypium hirsutum L. genotypes for combining ability studies of yield and quality traits. Igdir Uni. J. Inst. Sci. and Tech. 2: 67-74.

Shakoor, M.S., T.A. Malik, F.M. Azhar, M.F. Saleem. 2010. Genetics of agronomic and fiber traits in upland cotton under drought stress. Int. J. Agric. Biol. 12: 495-500.

Shanti, N., U. Selvaraj. 1995. Combining ability studies for quantitative characters in cotton ( $G$. hirsutum L.). Madras Agri. J. 82: 162-164.

Steel, R.G.D., J.H. Torrie, D. Dickey. 1997. Principles and Procedure of Statistics. A Biometrical Approach. 3. ed. McGraw-Hill Publ. Company.

Zeng, L. 2014. Broadening the genetic base of upland cotton in U.S. cultivars-genetic variation for lint yield and fiber quality in germplasm resources. In:World Cotton Germplasm Resources,ed.Abdurakhmonov, I. Y. ISBN 978953-51-1622-6, InTech, DOI: 10.5772/57606.

Zeng, L., Bechere, E., Boykin, D.L. 2014.Commonality analysis and selection of parents for within-boll yield components in upland cotton. Euphytica199: 339-348. 